\title{
Investigation of Optical Response of Gasochromic Thin Film Structures through Modelling of Their Transmission Spectra under Presence of Organic Vapor
}

\author{
J. Domaradzki*, M. Mazur, D. Wojcieszak, D. Kaczmarek and T. Jedrzejak \\ Faculty of Microsystem Electronics and Photonics, Wrocław University of Technology, \\ Z. Janiszewskiego 11/17, 50-372 Wrocław, Poland
}

(Received May 12, 2014; in final form March 18, 2015)

\begin{abstract}
Properties of chromogenics materials have been of great interest for more than 50 years till now. Some examples of their practical application are photochromic lenses, electrochromic smart windows or even some examples of sensors devices based on gasochromic thin films have already been commercially available on the market. However, recognition of different physical and chemical processes that influence the optical response of such materials under changes in surrounding atmosphere is still an open subject for discussion. This work presents results of experimental and theoretical investigations of optical response of the two selected gasochromic ( $\mathrm{Ti}-\mathrm{V}-\mathrm{Ta}-\mathrm{W}) \mathrm{Ox}$ and $(\mathrm{Ti}-\mathrm{V}-$ $\mathrm{Ta}-\mathrm{Nb}) \mathrm{Ox}$ oxide thin films under ethanol vapor stimulations. Based on the measured experimental transmission spectra, the complex refraction index characteristics were plotted using optical models elaborated for the VIS-NIR spectral range. The models were further used for the prediction of optical responses of optical gas sensing structures with observed gasochromic behavior.
\end{abstract}

DOI: 10.12693/APhysPolA.127.1702

PACS: 78.20.-e

\section{Introduction}

The principle of operation of most available gas sensors consists in detection and measurement of changes of an electrical property (resistivity) of the sensing material exposed to selected gas(es) and at appropriate, usually elevated, temperature. But in some of the materials, among change of the electrical properties, occurrence of optical effect has been recognized. This kind of materials belongs to so-called group of "chromic" (or "chromogenic") materials [1-3] for which the change in optical properties is a result of chemical or physical process induced by various external stimuli, e.g. optical UV irradiation. Changes in optical properties can be seen as a change in transparency or in a color of a material. Usually the process is reversible when the specific external factor is removed and the material comes back to its previous state.

To date, reports on the analysis of optical properties of gasochromic materials relies mostly on explanation of coloration mechanisms and they are very rare $[4,5]$. However, for i.e. designing of smart optical coatings with gasochromic property, the analysis of the complex refraction index changes in the gasochromic thin films under external gas environment is strongly required. This report presents some exemplary experimental and theoretical results of investigations of optical response of multicomponent oxide thin films under presence of air-ethanol vapor gas mixture. Ethanol has been chosen as a representative organic chemical compound that recently arose increasing interest of researchers from around the world.

\footnotetext{
* corresponding author; e-mail jaroslaw.domaradzki@pwr.edu.pl
}

\section{Experimental}

The multicomponent oxide thin films, denoted in this work as $(\mathrm{Ti}-\mathrm{V}-\mathrm{Ta}-\mathrm{Nb}) \mathrm{Ox}$ and $(\mathrm{Ti}-\mathrm{V}-\mathrm{Ta}-\mathrm{W}) \mathrm{Ox}$, were prepared by impulse magnetron sputtering process using metallic $\mathrm{Ti}-\mathrm{V}-\mathrm{Ta}-\mathrm{Nb}$ and $\mathrm{Ti}-\mathrm{V}-\mathrm{Ta}-\mathrm{W}$ mosaic targets, respectively. Oxides of selected transition metals belong to the most studied group of chromogenic materials [2-8]. For preparation of the oxide thin films the targets were sputtered in reactive oxygen plasma. The films were deposited on Corning 7059 type, $0.7 \mathrm{~mm}$ thick glass substrates. The thickness of deposited thin films was: $116 \mathrm{~nm}$ for $(\mathrm{Ti}, \mathrm{V}, \mathrm{Ta}, \mathrm{W}) \mathrm{Ox}$ and $308 \mathrm{~nm}$ for $(\mathrm{Ti}, \mathrm{V}, \mathrm{Ta}, \mathrm{Nb}) \mathrm{Ox}$. Details of the thin films preparation procedure used for the purpose of the present work were previously described in (e.g. [9-11]).

The atomic percent of elements in the prepared thin films was determined using Hitachi S-4700N scanning electron microscope equipped with Noran Vantage energy dispersive spectrometer. The amount of atomic percent of particular elements in the thin films, which are described in the current work, are: $\mathrm{Ti}-12.41, \mathrm{~V}-11.85$, Ta-5.6, Nb-0.72 and Ti-22.06, V-2.92, Ta-2.06, W-4.10 for (Ti-V-Ta-Nb) Ox and (Ti-V-Ta-W)Ox thin films, respectively.

X-ray diffraction (XRD) method was used to determine the crystal structure of prepared thin films. XRD spectra were recorded using Philips X'Pert powder diffractometer with $\mathrm{Cu} K_{\alpha}$ radiation in the range of $2 \theta$ between $10^{\circ}$ and $65^{\circ}$. However, it seems that the particles in the prepared thin films were too fine and no diffraction patterns were found, which indicates on amorphous behaviour of the prepared thin films. Therefore, X-ray photoelectron spectroscopy (XPS) has been applied to determine the chemical states of the elements at the surface of 
the thin films. Experiments were performed using Specs Phoibos 100 MCD-5 hemispherical analyser in an ultrahigh vacuum conditions by the aid of Specs XR-50 X-ray source with $\mathrm{Mg} K_{\alpha}(1253.6 \mathrm{eV})$ beam. Photoelectrons were collected at $45^{\circ}$ take-off-angle and analysed by a concentric hemispherical analyser. Data were collected in the range equivalent to $\mathrm{Ti} 2 p, \mathrm{O} 1 s, \mathrm{~V} 2 p$, Ta $4 f$, $\mathrm{Cr} 2 p, \mathrm{~W} 4 f$, and $\mathrm{Nb} 3 d$ states. All the spectra were calibrated with respect to the binding energy of adventitious $\mathrm{C} 1 s$ peak at $284.8 \mathrm{eV}$. XPS measurements have shown that in both manufactured films $\mathrm{TiO}_{2}, \mathrm{~V}_{2} \mathrm{O}_{5}$ and $\mathrm{Ta}_{2} \mathrm{O}_{5}$ forms occur. Additionally, depending on the kind of additional dopant $\mathrm{WO}_{3}$ or $\mathrm{Nb}_{2} \mathrm{O}_{5}$ phases were also detected. Surface analysis was performed with atomic force microscopy (AFM) investigations and average roughness of the films was evaluated as $2.81 \mathrm{~nm}$ for $(\mathrm{Ti}-\mathrm{V}-\mathrm{Ta}-$ $\mathrm{W}) \mathrm{Ox}$ and $1.65 \mathrm{~nm}$ for ( $\mathrm{Ti}-\mathrm{V}-\mathrm{Ta}-\mathrm{Nb}) \mathrm{Ox}$ thin films and the roughness distribution at the surface was homogeneous.

Gasochromic properties were investigated using experimental setup presented in Fig. 1. To provide the optical signal a coupled deuterium-halogen light source (Micropack DH-2000-BAL) was used. The samples were illuminated from the thin film side at a normal incidence. Light passing through the sample was then focused and acquired by Ocean Optics QE65000 scientific grade spectrophotometer working in the range of 200-1000 $\mathrm{nm}$. Small roughness of prepared films allows to neglect light scattering effect in further analysis. Coloration process was assured by supplying the chamber with vapor provided by a synthetic dry air flow through a bubbler filled with $99.6 \%$ purity ethanol. Bleaching process was assured by the flow of pure synthetic air through the cryostat. The measurements were carried out in steady state conditions after saturation of the thin film with ethanol vapor. The way how the experiment was carried out has already been described in our previous paper [12].

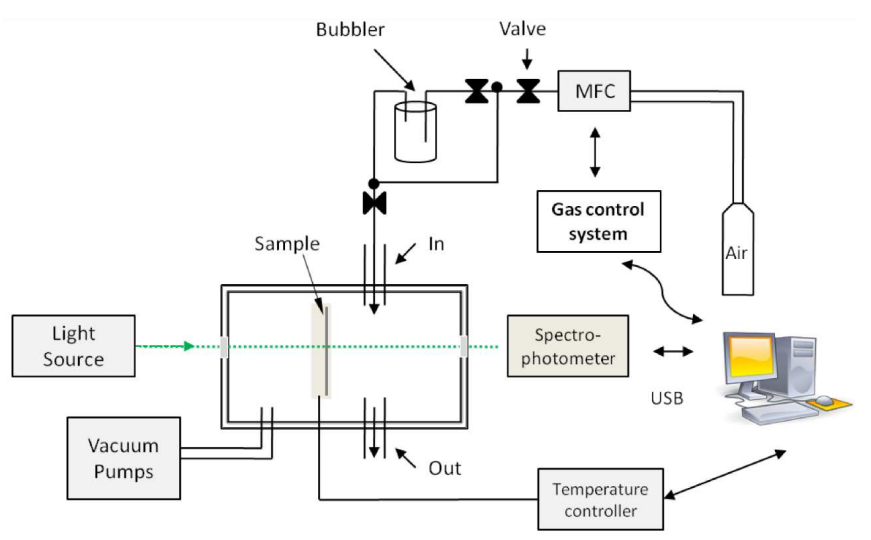

Fig. 1. Experimental setup for gasochromic investigations of thin films.

Analyses of theoretical studies were performed using SCOUT software package [13].

\section{Results and discussion}

\subsection{Results of optical investigations}

Figure 2 (symbols) presents measured transmission characteristics of investigated thin films. As one can see, both films were well transparent in the visible part of the light spectrum. Application of gas mixture containing ethanol vapor results in transparency decrease of the films in the wavelength range above $400 \mathrm{~nm}$. Observed dimming effect was as big as $28 \%$ and it was about twice deeper for the thin film containing $\mathrm{Nb}_{2} \mathrm{O}_{5}$. The observed process of coloring/bleaching was fully reversible and repeatable [12]. Collected optical transmittance spectra

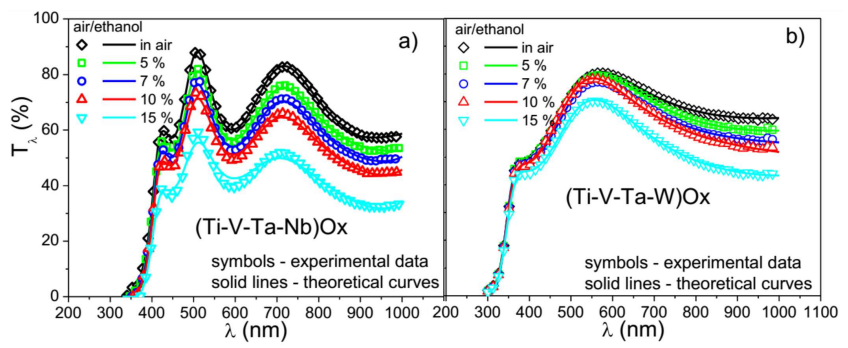

Fig. 2. Transmission characteristics of: (a) $(\mathrm{Ti}-\mathrm{V}-\mathrm{Ta}-$ $\mathrm{Nb}) \mathrm{Ox}$ and (b) ( $\mathrm{Ti}-\mathrm{V}-\mathrm{Ta}-\mathrm{W}) \mathrm{Ox}$ thin films recorded under different composition of air-ethanol gas mixture.

were further used for determination of the complex refraction index components. For calculation of theoretical transmission curves (solid lines, Fig. 2) the so-called reverse synthesis was applied using the SCOUT [13] software. The simple Sellmeier empirical dispersion model was first used, where refraction $(n)$ and extinction $(k)$ coefficients can be presented as functions slowly varying on the wavelength $(\lambda)$ :

$$
\begin{aligned}
& n=A+\frac{B}{\lambda^{2}}+\frac{C}{\lambda^{4}}, \\
& k=D * \exp \left(\frac{E}{\lambda}\right)^{2},
\end{aligned}
$$

where $A, B, C, D, E$ are fitting parameters.

However, this model was insufficient for description of absorption in shorter wavelength range, therefore the O'Leary-Johnson-Lim (OJL) model for interband transition was applied [14]. The best fits of the theoretical curves to the experimental ones are presented in Fig. 2 (solid lines).

Figure 3 presents spectral characteristics of calculated $n$ and $k$ components. From Fig. 3 it results that in the both considered samples the calculated spectra were dependent on the ethanol concentration in the vapor. Observed increase in light absorption given in Fig. 3b and $\mathrm{d}$ by $k$ value can be associated with an increase in electron concentration due to the interaction of the ethanol vapor molecules with the thin film surface $[4,5]$. What is noticeable, the characteristics of $n$ component elaborated for the $(\mathrm{Ti}-\mathrm{V}-\mathrm{Ta}-\mathrm{W}) \mathrm{Ox}$ were also changed but for $(\mathrm{Ti}-\mathrm{V}-\mathrm{Ta}-\mathrm{Nb}) \mathrm{Ox}$ remain almost the same. One of the possible reasons of this difference could be that in the 
case of thin film with tungsten, the saturation process of the thin film with ethanol results in changes in vibrational mode structure of $\mathrm{W}-\mathrm{O} \ldots \mathrm{OH}_{2}$ bounds as it was observed by Orel [5].
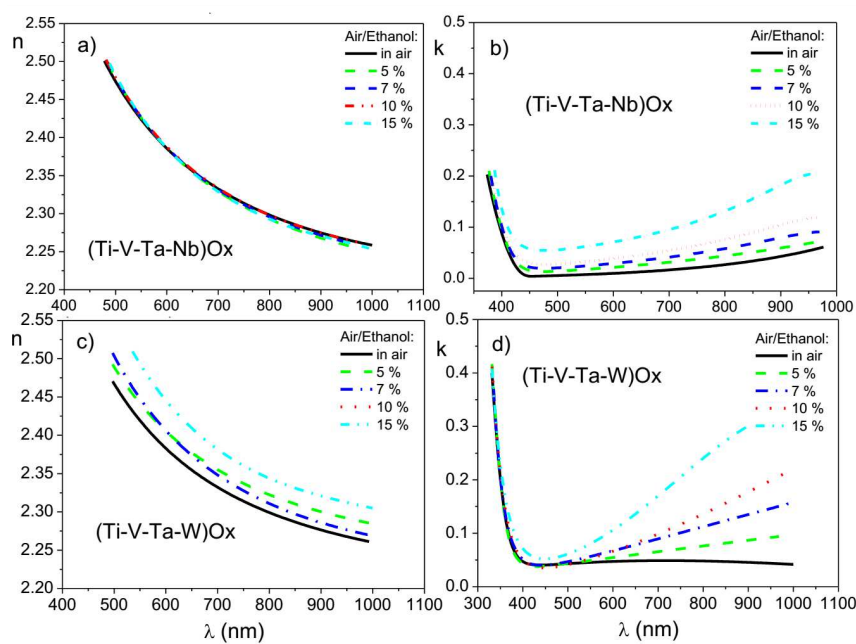

Fig. 3. The complex refractive index components: (a, c) $n$ and $(\mathrm{b}, \mathrm{d}) k$ evaluated for $(\mathrm{a}, \mathrm{b})(\mathrm{Ti}-\mathrm{V}-\mathrm{Ta}-$ $\mathrm{Nb}) \mathrm{Ox}$ and $(\mathrm{c}, \mathrm{d})(\mathrm{Ti}-\mathrm{V}-\mathrm{Ta}-\mathrm{W}) \mathrm{Ox}$ thin films under different ethanol vapor concentration.

\subsection{Results of computer simulations}

Calculated $n$ and $k$ spectra were further used for computer simulation of transmission characteristics of $(\mathrm{Ti}-$ $\mathrm{V}-\mathrm{Ta}-\mathrm{Nb}) \mathrm{Ox}$ and $(\mathrm{Ti}-\mathrm{V}-\mathrm{Ta}-\mathrm{W}) \mathrm{Ox}$ thin films with different thickness. For designing, the FilmStar Design software was used [15]. The results of theoretical studies are presented in Fig. 4.

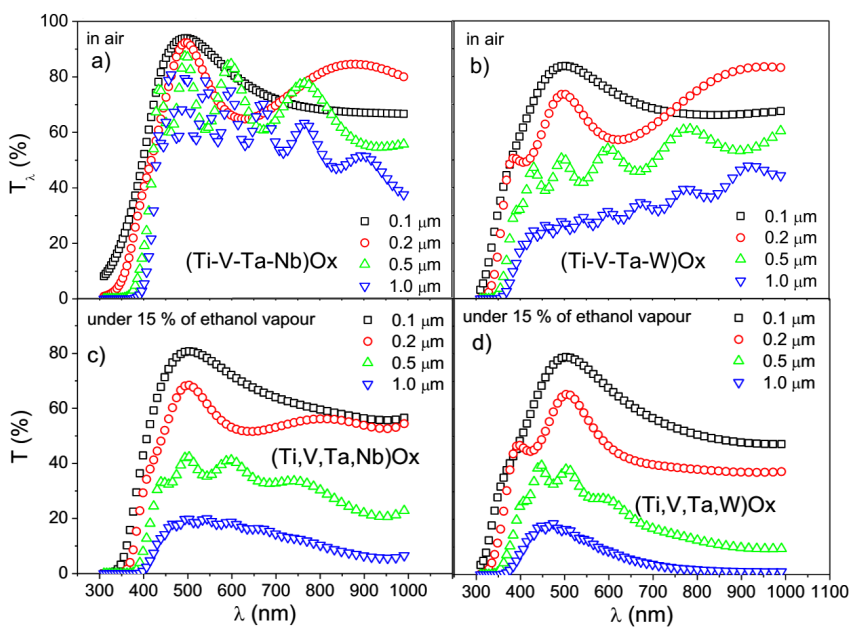

Fig. 4. Simulation results showing the dependence of transmittance vs. the thin film thickness for (a, c) ( $\mathrm{Ti}-$ $\mathrm{V}-\mathrm{Ta}-\mathrm{Nb}) \mathrm{Ox}$ and $(\mathrm{b}, \mathrm{d})(\mathrm{Ti}-\mathrm{V}-\mathrm{Ta}-\mathrm{W}) \mathrm{Ox}$ thin films: $(\mathrm{a}, \mathrm{b})$ in an air and $(\mathrm{c}, \mathrm{d})$ in gas mixture containing $15 \%$ of ethanol vapor.

Analysis of the theoretical characteristics allows us to conclude that the increase in the thin films thickness results in its average transparency decrease. However, this decrease is much more visible in case of the thin film containing tungsten oxide (Fig. $4 \mathrm{~b}$ ). Upon $15 \%$ of ethanol concentration in the vapor, the coloring effect is comparable in both investigated thin films (Fig. 4c,d).

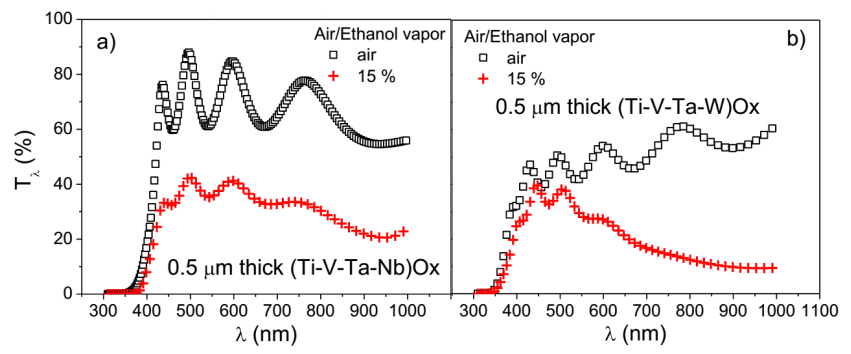

Fig. 5. Simulation results of the transmission coefficient characteristics for: (a) $(\mathrm{Ti}-\mathrm{V}-\mathrm{Ta}-\mathrm{Nb}) \mathrm{Ox}$ and (b) $(\mathrm{Ti}-\mathrm{V}-\mathrm{Ta}-\mathrm{W}) \mathrm{Ox}$ thin films in air and in the gas mixture containing $15 \%$ of ethanol vapor for selected thin film thickness.

Figure 5 presents comparison of simulated coloring/bleaching process of the thin films with selected thickness of $500 \mathrm{~nm}$. What is worth to point out is that the average change in transmission coefficient level for $(\mathrm{Ti}-\mathrm{V}-\mathrm{Ta}-\mathrm{Nb}) \mathrm{Ox}$ was about $40 \%$ in the whole investigated spectral range, whereas for $(\mathrm{Ti}-\mathrm{V}-\mathrm{Ta}-\mathrm{W}) \mathrm{Ox}$ it was more visible in a longer wavelength range. Choosing of an "optimal" film thickness in the case of real application is difficult. The film thickness is always the "right choice" a compromise between minimum thickness but adequate to observe an effect and too thick film that influence on, e.g. higher light absorption, appearance of interference fringes in transmission charts, and so on. Based on the presented results it can be concluded that the thickness of $100 \mathrm{~nm}$ should be appropriate in most cases of possible applications.

\section{Conclusions}

In the present work experimental results of optical transmission of selected oxide thin films measured in an air and in air-ethanol vapor gas environments were used in order to develop theoretical models for elaboration of their refraction and extinction coefficients. The models proved their usefulness in prediction of the optical response of investigated thin films with different thickness. The obtained results have shown that the predicted optical changes for the thin film containing tungsten, were more apparent in the longer wavelength range while for the $(\mathrm{Ti}-\mathrm{V}-\mathrm{Ta}-\mathrm{Nb}) \mathrm{Ox}$ thin film the decrease in optical transmission was almost constant in the whole investigated wavelength range. Such simulation results can be very helpful in the designing of different structures containing gasochromic thin films.

\section{Acknowledgments}

The work was financed from the sources granted by the NCN in the years 2011-2013 as a research project number N N515 496340 and by the sources given by NCBR in the years 2013-1016 as a project number PBS2/A5/33/2013. 


\section{References}

[1] C.G. Granquist, Sol. En. Mater. Sol. Cells 60, 201 (2000).

[2] M.H. Yacob, M. Brendon, K. Kalantar-Zadeh, W. Wlodarski, Sensor. Actuat. B Chem. 137, 115 (2009).

[3] A. Taurino, M. Catalano, P. Siciliano, E. Comini, G. Sberveglieri, Sensor. Actuat. B Chem. 92, 286 (2003).

[4] V. Wittwer, M. Datz, J. Elli, A. Georg, W. Graf, G. Walze, Sol. En. Mater. Sol. Cells 84, 305 (2004).

[5] B. Orel, M. Groselj, U. Opara Krasovec, M. Gabrsck, P. Bukovec, R. Reisfeld, Sensor. Actuat. B Chem. 50, 234 (1998).

[6] D. Schweiger, A. Georg, W. Graf, V. Wittwer, Sol. En. Mater. Sol. Cells 54, 99 (1998).

[7] H. Chen, N. Xu, S. Deng, D. Lu, Z. Li, J. Zhou, J. Chen, Nanotechnology 18, 205701 (2007).

[8] J.Z. Ou, M.H. Yacob, J.L. Campbell, M. Brendon, K. Kalantar-Zadeh, W. Wlodarski, Sensor. Actuat. B Chem. 166/167, 1 (2012).
[9] E.L. Prociów, J. Domaradzki, D. Kaczmarek, T. Berlicki, Polish patent PL 211827 B1 (2012).

[10] R. Wasielewski, J. Domaradzki, D. Wojcieszak, D. Kaczmarek, A. Borkowska, E. Prociów, A. Ciszewski, Appl. Surf. Sci. 254, 4396 (2008).

[11] J. Domaradzki, E. Prociów, D. Kaczmarek, D. Wojcieszak, D. Gatner, M. Lapiński, Acta Phys. Pol. A 116, S-126 (2009).

[12] J. Domaradzki, D. Kaczmarek, D. Wojcieszak, M. Mazur, Sensors Actuat. B Chem. 201, 420 (2014).

[13] W. Theiss, SCOUT ver. 2.3, www.mtheiss.com.

[14] S.K. O'Leary, S.R. Johnson, P.K. Lim, J. Appl. Phys. 82, 3334 (1997).

[15] FilmStar Optical Thin Film Software, Design, www.ftgsoftware.com/design.htm. 